The University of San Francisco

USF Scholarship: a digital repository @ Gleeson Library |

Geschke Center

1998

\title{
Currently Accepted Practices That Are Known to Lead to Death, and PAS: Is There an Ethically Relevant Difference?
}

Thomas A. Cavanaugh

University of San Francisco, cavanaught@usfca.edu

Follow this and additional works at: http://repository.usfca.edu/phil

Part of the Ethics and Political Philosophy Commons

\section{Recommended Citation}

Cavanaugh, Thomas A., "Currently Accepted Practices That Are Known to Lead to Death, and PAS: Is There an Ethically Relevant Difference?" (1998). Philosophy. Paper 14.

http://repository.usfca.edu/phil/14 


\title{
Currently Accepted Practices That Are Known to Lead to Death, and PAS: Is There an Ethically Relevant Difference?
}

\author{
THOMAS A. CAVANAUGH
}

A number of common and generally noncontroversial practices in the care of patients at the end of life lead to their deaths. For example, physicians honor a patient's refusal of medical intervention even when doing so leads to the patient's death. Similarly, with a patient's or surrogate's consent, physicians administer sedatives in order to relieve pain and distress at the end of life, even when it is known that doing so will cause the patient's death. In contemporary U.S. public policy, these practices are accepted as ethical and legal while physicianassisted suicide (PAS) is - for the most part-rejected in current U.S. law and public policy. Some think, however, that if one accepts practices that are known to lead to a patient's death, then one cannot reasonably reject a patient's request for a lethal dose of medication so that she may kill herself (PAS). ${ }^{1}$

In what follows, I argue that there are ethically significant differences between PAS and the currently accepted practices in terms of which one may accept these practices while rejecting PAS. I do so by contrasting PAS with: first, the refusal of medical care resulting in death; second, the forgoing or withdrawal of medical measures that leads to death; third and finally, palliative sedation that causes death. After noting the relevant differences between the refusal of medical intervention and PAS, I argue that the fundamental ethical difference between forgoing, withdrawing, and palliative sedation, on the one hand, and PAS, on the other, is that PAS necessarily involves deliberate, intentional killing while these other practices do not. Moreover, I argue that this is an ethically important difference in terms of which it is reasonable to accept the currently accepted practices while rejecting PAS.

\section{Refusal of Medical Interventions and PAS}

A. H. Clough's famous line, "Thou shalt not kill but need'st not strive officiously to keep alive," although it was not his intent, articulates the status quo and-as I argue in what follows-the appropriate balance in medical acts at the end of life. ${ }^{2}$ Indeed, practitioners, patients, and the general public are coming to the realization that when medical intervention imposes a greater burden than benefit, one ought not strive to keep alive. Law and ethics acknowledge this by recognizing a patient's legal and ethical right to refuse medical interventions. Some argue, however, that since a physician must honor a patient's refusal of medical intervention - and must do so even when death is ensured by this refusal-then a patient ought to have the right to a physician's assistance in killing herself. ${ }^{3}$ If death is the certain effect of a patient's refusal of antibiotics, for example, and death is the certain result of giving a prescription 
of a lethal drug to a patient who intends to take the lethal dose, then how do the two practices differ?

The refusal of medical intervention that leads to death can be differentiated from PAS in terms of the physician-patient relationship. Specifically, if a patient does not have the right to refuse medical intervention and a physician does not have the obligation to honor this refusal, what is the alternative way of working out the physician-patient relationship? The alternative would be that the physician has the right to mandate medical intervention and the patient has the obligation to accept it. This, however, is not tolerable. For human beings are uniquely suited to live in accordance with their own apprehension of what is good; that is, human beings are appropriately self-ruled. A society that obligates patients to undertake the medical interventions proposed by physicians acts against the nature of the human subject by subordinating him to the will of another, identifiable individual.

On the other hand, to refuse to entitle patients to the assistance of physicians in suicide limits only the means patients may employ to achieve their goals. It does not thereby subordinate them to any other individual's will; indeed, it does not prevent them from committing suicide, if they can do so without another's assistance. Those who argue that the right to refuse medical intervention cannot consistently be accepted without thereby accepting PAS fail to reflect sufficiently on the alternative to honoring the right to refuse.

Moreover, even if a suicidal patient seeks to ensure her death by refusing medical intervention and her physician and society honor her refusal, her refusal need not be accepted as a suicide. It need be accepted solely as a refusal of medical intervention. Those who argue that one cannot reasonably accept the suicidal refusal of medical intervention while rejecting PAS fail to note that what is being accepted is the suicidal refusal of medical intervention not the suicidal refusal of medical intervention. If physicians and society were to accept PAS, however, they would necessarily accept and participate in the act as a suicide. Since it is reasonable-as I argue below - to regard a patient's death as harmful to the patient, it is reasonable to reject a patient's request that one assist him to commit suicide. Thus, one can honor the right to refuse medical interventions while reasonably rejecting the legitimacy of PAS. I now turn to a comparison of PAS to forgoing and withdrawing medical interventions.

\section{Forgoing, Withdrawing, and PAS}

Currently, patients, surrogates, physicians, and nurses forgo or withdraw measures such as antibiotics, ventilator-support, and dialysis knowing that death will occur if these measures are not employed. Advocates of PAS ask how one contrasts forgoing and withdrawing from providing a patient with a lethal dose of medication so that she may kill herself. Of course, forgoing and withdrawing medical interventions at the end of life are often categorized as allowing death while PAS is categorized as a killing. Thus, the debate often concerns whether there is an ethically relevant difference between causing death and allowing death, or between killing and letting die.

Much has been written in bioethics and ethics more generally concerning three issues implicated in this debate: first, what is a causing, doing, making, or killing; second, what is an allowing, permitting, accepting, or letting die; and, third, is there an ethically relevant difference between killing and letting die such that other 
things being equal, killing is worse than letting die? ${ }^{4}$ I cannot enumerate all of the relevant points. I can, however, clarify a number of crucial ones.

What is a causing and what is an allowing? Basically, a cause is that from which or on account of which some effect is or is the way it is and that without which some effect would not be or would not be the way it is. Allowing is parasitic on causing, for allowing requires that there be some cause other than oneself. Moreover, one must be able to prevent the cause from bringing about its effect. Thus, allowing has two concepts prior to it: causing and preventing. If one can and knowingly and without coercion does not prevent the cause from bringing about its effect, one allows the effect. Accordingly, allowing is not opposed to causing; allowing is opposed to preventing.

Is forgoing ventilator support, antibiotics, or dialysis at the end of life when doing so results in death an allowing to die? It seems to be insofar as death is the effect of an underlying physiological cause that one can but does not prevent. On the other hand, it is not an allowing death simpliciter insofar as death cannot be prevented, but only can be forestalled, put off, postponed. Might one conclude from the inevitability of death that one cannot prevent death, and, therefore, that one can never really allow it either? This would be to go too far. For example, when a lifeguard rescues a swimmer from drowning, she does not prevent him from dying altogether-he will die some day and from something-but she does prevent him from dying from drowning on this occasion. Moreover, the swimmer's death is not otherwise imminent. Thus, if a lifeguard could but did not prevent the swimmer from drowning, she would be allowing him to die.

Such cases differ, however, from those at the end of life. For in cases at the end of life, what a person will die from has asserted itself. Death from an identified cause or network of causes is known to be imminent. Since one cannot prevent death from these causes at the end of life, it is not true to say that one allows death to occur from these causes at the end of life. What does one do? In the cases of forgoing in question, one can prevent death from occurring at an earlier rather than a later time. Therefore, in such cases, one allows death to occur at an earlier time.

Insofar as they involve causing, cases of withdrawing medical measures at the end of life initially seem more complicated than cases of forgoing. That is, withdrawings involve doing things like turning machines off and removing tubes. It might seem puzzling to assert that a causing is an allowing. It is a mistake, however, to make too much of this seeming paradox or of the putative oxymoronic character of "causing an allowing." For, as noted, allowing is not opposed to causing; allowing is opposed to preventing. Once this is realized the initial puzzle about cases of withdrawings being allowings disappears. For when one employs measures such as ventilators at the end of life, one prevents death from occurring at an earlier rather than a later time. Thus, when one stops preventing death, one allows death at an earlier rather than a later time. Accordingly, withdrawings are allowings because they are instances in which one stops preventing.

Turning to PAS, there is the patient's taking and the physician's prescribing of a lethal drug. In taking a lethal drug, the patient causes his death. Moreover, he does so on purpose: he takes the drug in order to kill himself. Similarly, the physician gives the patient a prescription so that he may kill himself. She assists in causing an intended death. Thus, in PAS death is caused and intended. 


\section{Thomas A. Cavanaugh}

Forgoings and withdrawings differ from PAS in at least two ways. Forgoings and withdrawings allow death, while PAS causes death. As noted earlier, some focus on this difference asserting that killing significantly differs from allowing to die. ${ }^{5}$ In cases at the end of life, however, this is not the ethically relevant difference in terms of which one distinguishes forgoings and withdrawings from PAS. To see this, consider a currently accepted practice that, like PAS, is an instance in which the patient dies, not from some underlying physiological disease, but from a cause posited by an agent. I refer to some instances of palliative sedation at the end of life that both relieve pain and-by suppressing respiration-cause death. By examining palliative sedation that causes death, the criterion in terms of which one accepts the currently accepted practices that lead to death while rejecting PAS becomes evident.

\section{Foreseeably Causing Death and PAS}

Sometimes in order to relieve pain and distress at the end of life it is necessary to sedate a patient. ${ }^{6}$ Doing so may cause the patient's death. Such acts, although they cause death, are legal and-as I argue in what follows-ethical. Indeed, given a physician's obligation to relieve a patient's pain, such acts are at times obligatory. However, unlike accepted practices that allow death, palliative sedation-like PAS-causes death. This similarity has led some to argue that one cannot reasonably accept palliative sedation while rejecting PAS. ${ }^{7}$ Certainly, it is not in terms of the causing death/letting die distinction that one rejects PAS while accepting palliative sedation. Therefore, if the rejection of PAS is not arbitrary, there must be an ethically relevant difference-other than the killing/ letting die distinction-in terms of which palliative sedation, forgoing, and withdrawing can be distinguished from PAS.

There is an ethically significant difference between PAS on the one hand and palliative sedation, forgoing, and withdrawing on the other. That difference concerns the differing intentional structures of these practices. For some act to count as an instance of PAS, it is necessary that the patient intend his own death and that the physician intend to assist her patient in killing himself. In PAS the patient's death is necessarily intended. In palliative sedation death is not intended, although it is known that the sedative will cause death. The same holds true of forgoing and withdrawing. Accordingly, the central distinction at issue between PAS and the currently accepted practices is that between an intended effect and a foreseen but not intended side-effect or concomitant-the intended/foreseen (I/F) distinction.

Before considering whether this is an ethically significant distinction, two objections need to be addressed. First, someone might object to the assertion that death is necessarily intended in PAS while in the other practices in question it is not. For in palliative sedation, forgoing, and withdrawing although it is not necessary, it is possible that death is intended. Do such cases differ from PAS? There are two relevant considerations. First, if the point of administering a sedative, for example, were to kill the patient, then such an act, although to an observer it might look like palliative sedation, would not be palliative sedation, but would be active euthanasia, insofar as an act is defined by the agent's intent and not by appearances. Second, from the standpoint of public policy, such acts are not accepted as deliberate, intentional killings, although by accepting palliative sedation one might inevitably end up accepting acts that 
masquerade as instances of palliative sedation. The same holds true for cases of forgoing or withdrawing medical interventions at the end of life in which the point is to ensure death. As said earlier, these acts are accepted as refusals of medical intervention.

The second objection that requires attention concerns the assumption that death harms the patient and is, therefore, to be avoided at the end of life. Of course, this assumption may be at issue with those who propose PAS. Proponents of PAS might consider death beneficial to the one who would be killed. Given the centrality of this assumption, before going on to consider the ethical relevance of the I/F distinction it is necessary to examine the reason for holding that death itself harms the one who dies, and that, therefore, one ought not to intend the harm of death.

Death ends a person's existence. After a person dies, he or she no longer exists. Death destroys the human being. As the destruction of the human being, death fundamentally harms and is bad for the human being. Some might object that we sometimes reasonably think that a person is "better off dead" and that in such cases, death benefits the person who dies. However, insofar as the human being no longer exists after she dies, she cannot be said to be "better off dead." When one says that some person is better off dead, one is not comparing her condition before death with her condition after death, because she does not have any condition after death with which to compare her condition before death. What does one mean? One compares different lengths and conditions of life and says that it is better that someone lived up to time $t$ than that she lived up to time $(t+n)$. In saying that living up to time $t$ is better than living up to time $(t+n)$, one need not be committed to any judgment concerning the goodness of death, for one can make sense of what is being said entirely in terms of the goodness of being alive in certain conditions. That is, one compares the goodness of being alive in a certain condition up to but not after time $t$ to the goodness of being alive in a certain condition up to and after time $t$. Having addressed these objections, I now argue for the ethical relevance of the intended/foreseen (I/F) distinction.

\section{The Intended/Foreseen Distinction's Ethical Significance}

To argue for the ethical significance of the I/F distinction, it is first necessary to clarify what the distinction distinguishes. It does not, as its advocates sometimes propose (and as its name suggests) distinguish between desires and beliefs or between will and knowledge or between the volitional and the epistemic. Rather, it distinguishes between different volitional attitudes agents have to consequentially similar effects.

In palliative sedation, for example, the physician not only believes that death will come about, but believing that it will come about, he knowingly and without coercion, or voluntarily, causes it. Although he does not want the patient's death for its own sake as an end, nor for the sake of something else as a means, he would rather relieve his patient's pain and cause her death than forgo relieving her pain and not cause her death. He wants to relieve pain more than he wants not to cause death. As applied to PAS and palliative sedation the $\mathrm{I} / \mathrm{F}$ distinction contrasts the two acts in terms of the volitional states definitive of each act. The volitional state defining PAS is that of willing death as a means to ending a life judged by the one living it as no longer worth living. The state 


\section{Thomas A. Cavanaugh}

implicated in palliative sedation is that of willing to relieve pain more than one wills not to cause death. To determine whether these volitional states differ in an ethically significant way, one first must establish what constitutes ethical relevance.

\section{The Voluntary}

Ethics concerns the goodness and badness of both what humans believingly and willingly cause-acts-and what humans believingly and willingly do not cause-omissions. By "believingly and willingly" causing I mean a human being causing something voluntarily, which would exclude what is not up to him to cause and what he causes either in inculpable ignorance or by force. The voluntary is ethics' breadth. For something to be considered within ethics, it must fall within the bounds defined by belief and volition.

Ethics also has a depth that volition demarcates. It is in terms of this depth that the I/F distinction has ethical relevance. Insofar as an act is constituted by what an agent believingly and willingly causes, and insofar as willing admits of distinct depths-willing an end, willing a means, and willing to cause a concomitant-the goodness and badness of acts that cause consequentially similar states of affairs vary partly in accordance with the different volitional states that constitute the different acts. That is, other things being equal, an act that brings about a bad state of affairs as an end is worse than one that brings a consequentially similar bad state of affairs about as a means. Moreover, an act that brings a bad state of affairs about as a concomitant is not as bad as acts that bring similar consequences about as an end or as a means. In short, the goodness and badness of acts vary in part with the depth with which good and bad states of affairs are willed, such that the more deeply some good or bad state of affairs is willed, the better or the worse the act. For the act is in part that depth of willing that good or bad state of affairs.

One who would hold that differences in willing do not make for ethically significant differences must explain why believing and willing demarcate ethics, while the variations of which willing admits make no ethical difference. Ethics is mute if I benefit or harm you in blameless ignorance or by force-if I am tripped and fall on you. Yet ethics has much to say if I voluntarily harm or help you. It puzzles to hold that belief and volition have fundamental importance in ethics - by establishing that an act occurred-while holding that further differences of which willing admits have no ethical import. Such a position is out of sync with ethics' central concern with the voluntary. Just as good and bad states of affairs partially constitute ethical goodness and badness insofar as agents believingly and willingly cause those good and bad states of affairs, so also the depths of which willing admits - as an end, as a means, or as a concomitant-have ethical relevance.

I now return to the question concerning the ethical difference between the volitional states definitive of PAS and palliative sedation. Since the death of a patient harms the patient, in accordance with the above argument concerning the ethical relevance of volitional states, just as it is worse to kill just for the sake of killing than it is to kill for the sake of ending suffering (PAS), so also it is worse to kill in order to end suffering (PAS) than it is to relieve pain knowing that by doing so one will cause death (palliative sedation). For in PAS one wills a bad thing, the patient's death, more deeply than one does so in palliative 
sedation. In palliative sedation, one wills the patient's death only insofar as one would rather relieve pain and cause death than forgo relieving pain and avoid causing the patient's death. Therefore, palliative sedation is more justifiable than PAS. ${ }^{8}$ The same holds true for forgoing and withdrawing medical interventions at the end of life. Thus, in terms of the intended/foreseen distinction, one may reasonably accept (as much current U.S. public policy and law does) palliative sedation and acts of forgoing or withdrawing medical interventions at the end of life that lead to a patient's death while rejecting PAS.

\section{Notes}

1. See, for example, the majority's opinion in Compassion in Dying v. State of Washington, Case no. 94-35534, U.S. Court of Appeals for the Ninth Circuit, 79 F.3d 790 (9th Cir. 1996); and in Quill v. Dennis C. Vacco, U.S. Court of Appeals for the Second Circuit, 80 F.3d 716 (2nd Cir. 1996).

2. Clough AH. The latest decalogue. In: Gardner H, ed. The New Oxford Book of English Verse. Oxford: Oxford University Press, 1978.

3. See, for example, the majority's opinion in Compassion in Dying v. State of Washington, Case no. 94-35534, U.S. Court of Appeals for the Ninth Circuit, 79 F.3d 790 (9th Cir. 1996), p. 21; and in Quill v. Dennis C. Vacco, U.S. Court of Appeals for the Second Circuit, 80 F.3d 716 (2nd Cir. 1996), p. 23.

4. See, for example, Steinbock B, Norcross A, eds. Killing and Letting Die, 2nd ed. New York: Fordham University Press, 1994; and Jonathan Bennett's exhaustive treatment of the doing/ allowing distinction in Bennett J. The Act Itself. Oxford: Clarendon Press, 1995.

5. See, for example, Callahan D. When self-determination runs amok. Hastings Center Report 1992;22(2):52-5; and Brody B. Life and Death Decision Making. Oxford: Oxford University Press, 1988:24.

6. See, for example, Ira Byock's description of such a case in Byock I. Dying Well: The Prospect for Growth at the End of Life. New York: Riverhead Books, 1997:209-16.

7. See note 1, Compassion in Dying (1996), Quill (1996).

8. To say that an act $x$ is more justifiable than an act $y$ one must hold that act $x$ is justifiable. One need not, however, hold that act $y$ is justifiable. That is, one can hold that act $x$ is more justifiable than act $y$ while holding that act $y$ is not justifiable. Thus, in asserting that the currently accepted practices are more justifiable than PAS, I am holding that they are justifiable, while I am not necessarily holding that PAS is justifiable. 